\title{
REGISTRO CIVIL DE CRIANÇAS NASCIDAS DE GESTAÇÃO DE SUBSTITUIÇÃO NO BRASIL: UMA ANÁLISE A PARTIR DE JULGAMENTOS PELO TRIBUNAL SUPREMO ESPANHOL
}

\section{THE CIVIL REGISTRY OF CHILDREN BORN OF SURROGACY PREGNANCY: AN INVESTIGATION BASED ON RECENT SPAIN SUPREME COURT JUDGMENTS}

\author{
${ }^{1}$ Anna Cristina de Carvalho Rettore \\ ${ }^{2}$ Maria de Fátima Freire de Sá
}

\section{RESUMO}

No direito alienígena tem havido intensos debates acerca do registro civil de crianças nascidas a partir da técnica de gestação de substituição, quando esse nascimento ocorre em desconformidade com normas do país. Assim, à luz de recentes julgamentos pelo Tribunal Supremo espanhol - adotando-se, portanto, uma investigação jurídico-comparativa, por meio de fontes primárias e secundárias - busca-se responder se no Brasil, onde inexiste legislação federal expressa, mas vige Resolução do Conselho Federal de Medicina com parâmetros para a prática, o registro de crianças nascidas fora desses parâmetros (o que se pretende demonstrar não ser incomum) deve ou não ser facilitado.

Palavras-chave: Biodireito, Gestação de substituição, Registro civil

\begin{abstract}
In foreign law, there has been intense debates concerning civil registry of children born of surrogacy pregnancy, when such birth disrespects the country's norms. Thus, based on the analysis of recent Spain Supreme Court judgments - that is, through a juridical-comparative investigation, using primary and secondary sources -, and considering that although Brazil lacks an express federal law about the issue, a Resolution of the Federal Counsel of Medicine establishing parameters is being generally applied, the paper aims to answer whether or not Brazilian registry should be facilitated for births (demonstrated as not uncommon) that disregard such parameters.
\end{abstract}

Keywords: Biolaw, Surrogacy pregnancy, Civil registry

\footnotetext{
${ }^{1}$ Mestrando em Direito na Pontifícia Universidade Católica de Minas Gerais - PUC, Belo Horizonte - MG (Brasil). E-mail: annacriscr@gmail.com

${ }^{2}$ Doutora em Direito pela Universidade Federal de Minas Gerais - UFMG, Belo Horizonte - MG (Brasil). Professora da Pontifícia Universidade Católica de Minas Gerais - PUC, Belo Horizonte - MG (Brasil). E-mail: $\underline{\text { mfatimasa@uol.com.br }}$
} 


\section{INTRODUÇÃO}

Se, no passado, uma "ordem natural das coisas" impunha que a reprodução humana se desse apenas por meio da relação sexual entre um homem e uma mulher, sem uma exata compreensão de seu mecanismo, atualmente é possível afirmar com segurança a inexistência de vínculo necessário entre sexualidade e reprodução (ALMEIDA, 2009, p. 91). O conhecimento científico possibilitou o controle humano sobre o processo reprodutivo, tanto para evitá-lo (por métodos contraceptivos) quanto para promovê-lo (por meio de soluções para a infertilidade).

Nesse contexto, foram disponibilizadas variadas técnicas de reprodução humana assistida, como são exemplo a fertilização in vitro e a inseminação artificial, permitindo que indivíduos outrora excluídos da possibilidade de se reproduzir pudessem passar a optar por fazê-lo - adiante denominados pais intencionais - uma vez que não necessariamente há vínculo biológico deles com a criança a nascer, e que o vínculo de filiação nesse caso deve se constituir antes mesmo do desenvolvimento de qualquer socioafetividade.

Havia ainda, contudo, pessoas impedidas não (apenas) de gerar gametas férteis, mas de gestar a criança, como no caso de casais homoafetivos masculinos, homens solteiros, mulheres de idade avançada ou com questão de saúde que impedisse/contraindicasse a gestação (LAMM, 2012, p. 78). Para esses casos, a tecnologia biomédica passou a apresentar como solução a possibilidade de uso do útero de outrem - que pode ou não contribuir também com seus gametas - , por meio do que se convencionou chamar gestação de substituição ${ }^{l}$.

Não se pode dizer que o fenômeno seja exatamente novo, na medida em que na Bíblia já se descrevia pedido de Sara a Abraão: "Javé não me deixa ter filhos: una-se à minha escrava para ver se ela me dá filhos" (GÊNESIS, 1990, p. 27), em nítida assunção da possibilidade de se considerar mãe não aquela que gesta, mas aquela que intenta ter o filho. Ainda assim, contudo, as possibilidades recém trazidas pelas técnicas de reprodução humana assistida têm obrigado o reexame de institutos jurídicos consolidados, como a presunção de maternidade pelo parto e os conceitos de filiação e de família.

1 O termo "gestação de substituição" é utilizado pelo Conselho Federal de Medicina na Resolução n. ${ }^{\circ}$ 2.121/2015, e dá título à seção que trata do tema: "VII - SOBRE A GESTAÇÃO DE SUBSTITUIÇÃO (DOAÇÃO TEMPORÁRIA DO ÚTERO)” (CONSELHO FEDERAL DE MEDICINA, 2015). 
No Brasil, conquanto não haja, até o presente momento, texto de legislação federal expressa acerca do uso da técnica de reprodução humana assistida denominada útero de substituição, vige a Resolução do Conselho Federal de Medicina (CFM) n. ${ }^{\circ}$ 2.121/2015, que permite a prática segundo determinadas condições estabelecidas pelo próprio órgão. No entanto, procedimentos posteriores ao nascimento - que também correspondem a aspectos jurídicos do próprio planejamento familiar, por estar relacionado à segurança jurídica da criança que irá nascer - fogem da alçada de referida Resolução, restando, portanto, não regulamentados de maneira específica no Brasil. Por tal razão, em 14 de março de 2016, o Conselho Nacional de Justiça (CNJ) editou novo Provimento, de ${ }^{\circ}{ }^{\circ} 52$, que facilita o registro da criança nascida a partir da técnica.

Cabe, no entanto, o questionamento: no caso de criança nascida em desrespeito à vigente normatividade do CFM, o registro poderá ser feito nos facilitados termos do mencionado Provimento do CNJ? A questão se justifica tendo em vista que, não obstante a discussão ainda seja incipiente no Brasil, o registro de crianças oriundas da realização da técnica - seja clandestinamente no próprio país, seja em algum outro cuja legislação permita a prática - tem gerado intensos debates judiciais em países como a Espanha, a França e a Alemanha (CARAVACA; GONZÁLEZ, 2015, p. 69), quando a prática se dá em desconformidade com a legislação de onde se pretende efetivar esse registro.

$\mathrm{Na}$ busca pela resolução do problema apresentado, adotou-se como metodologia uma investigação jurídico-comparativa, que se presta "à identificação de similitudes e diferenças de normas e instituições em dois ou mais sistemas jurídicos" e onde é "geralmente introduzido o raciocínio analógico" (GUSTIN; DIAS, 2006, p. 29).

A comparação de institutos se dará especialmente entre o direito brasileiro e o espanhol, razão pela qual se objetiva que o estudo parta de recentes decisões do Tribunal Supremo da Espanha com relação ao registro civil espanhol de uma criança nascida a partir de gestação de substituição, por iniciativa de um casal homoafetivo espanhol, na Califórnia Estados Unidos, onde a prática é permitida, inclusive se onerosa. Para tanto, foram utilizadas fontes primárias (legislação, jurisprudência e pesquisa quantitativa em website referente à técnica) e secundárias (artigos de periódicos e livros de doutrina).

Assim, o trabalho tem início com o estudo da normatividade brasileira, especialmente a Resolução n. ${ }^{\circ}$ 2.121/2015 do CFM e do Provimento n. ${ }^{\circ}$ 52/2016 do CNJ, partindo-se para um diagnóstico da realidade no país - e a inevitabilidade da busca pela realização da técnica de gestação de substituição em desconformidade com determinados 
requisitos postos pelo CFM. Em seguida, são investigados dois acórdãos proferidos pelo Tribunal Supremo espanhol para, ao fim, a partir da comparação de institutos do direito brasileiro e do espanhol, justificar a resposta ao problema inicialmente proposto, acerca da possibilidade de aplicação do referido Provimento a casos que não atendem todos os requisitos da Resolução.

\section{O PANORAMA BRASILEIRO: REALIZAÇÃO DA TÉCNICA E REGISTRO DA CRIANÇA}

\subsection{Os requisitos da Resolução n. ${ }^{\circ}$ 2.121/2015 do Conselho Federal de Medicina}

No Brasil, atualmente, inexiste legislação que trate expressamente sobre o tema da gestação de substituição. Por esse motivo, a despeito da possibilidade de aplicação direta de normas constitucionais aos casos concretos (TEPEDINO, 2003, p. 130; ROBERTO, 2008, p. 89; FIUZA, 2012, p. 210), a doutrina fala em "vazio legislativo" (TEIXEIRA, 2004, p. 313), bem como que "a realidade viva reclam[a] regulamentação legislativa" (FARIAS, 2015, p. 255).

Em razão da ausência de texto de lei federal expresso, o Conselho Federal de Medicina vem, desde 1992, editando uma série de Resoluções com normas deontológicas a serem seguidas pelos médicos que viabilizam o acesso da população às técnicas de reprodução assistida, de tal modo que, conquanto as normas, cuja natureza é administrativa e não jurídica, dirijam-se exclusivamente aos profissionais da medicina, acabam, na prática, por gerar efeitos para todas as pessoas no país.

A norma em vigor, no momento, é a Resolução n. ${ }^{\circ}$ 2.121/2015 do Conselho Federal de Medicina, ${ }^{2}$ sendo, no entanto, imprescindível destacar a existência de entendimento doutrinário no sentido de que "os comandos existentes na citada norma administrativa não têm eficácia jurídica, além de serem fruto de decisões tomadas por órgão corporativo, sem qualquer caráter representativo do corpo social” (GAMA, 2001, p. 543). Dada a ausência de

\footnotetext{
${ }^{2}$ Essa norma revogou a anterior, de n. ${ }^{\circ}$ 2013/2013, sendo que na de 2013 havia a previsão da existência de "contrato" entre os pacientes e a cedente do útero, o que passou a ser qualificado como "termo de compromisso" em 2015; antes dela, vigeram no Brasil as Resoluções CFM de n. ${ }^{\circ}$ 1957/2010 e 1358/1992.
} 

lei federal, é possível, portanto, afirmar-se que o nascimento de uma criança segundo prática que não se adeque a todos os termos estabelecidos pelo Conselho não é conduta efetivamente proibida no Brasil, o que, por si, não se presta a reduzir a dimensão de importância da norma administrativa, a qual, como visto, tem majoritariamente norteado a realização da técnica em nosso país.

Assim, tem-se que em seu item VII, a referida Resolução determina: (i) que a técnica poderá ser utilizada apenas nos casos onde exista um "problema médico que impeça ou contraindique a gestação na doadora genética ou em caso de união homoafetiva"; (ii) que a gestante tenha parentesco consanguíneo até o quarto grau com um dos pacientes que requereram o uso da técnica, devendo os demais casos serem submetidos à avaliação do próprio Conselho, bem como que, se for casada ou viver em união estável, haja autorização por escrito de seu cônjuge ou companheiro; (iii) que não haja caráter lucrativo ou comercial, garantindose, no entanto, o pagamento pelos pacientes de tratamento e acompanhamento médicos da gestante; (iv) o preenchimento pelos envolvidos de termo de consentimento livre e esclarecido, que serão submetidos a avaliação psicológica; (v) o preenchimento pelos envolvidos de termo de compromisso "estabelecendo claramente a questão da filiação da criança"; e (vi) a garantia do registro civil da criança pelos pacientes que requereram a técnica (CONSELHO FEDERAL DE MEDICINA, 2015).

Observa-se que a Resolução exige apenas que os pais intencionais garantam que farão o registro da criança como filho(a) após o nascimento, bem como que haja termo que estabeleça a filiação de maneira clara. No entanto, tais "garantias" atêm-se apenas aos envolvidos e não são necessariamente cogentes, nem para eles, nem para demais órgãos brasileiros (como Cartórios de Registro Civil), o que já gerou uma série de situações de insegurança jurídica posteriores ao nascimento da criança, como ora se passa a demonstrar.

\subsection{A facilitação do registro pelo Provimento n. ${ }^{\circ} 52$ do Conselho Nacional de Justiça}

Na prática, a gestação de substituição tem sido realizada há anos no Brasil, nos termos da norma do Conselho. A título exemplificativo da possibilidade que a técnica representa no auxílio de pessoas no exercício do livre planejamento familiar, em Belo Horizonte/MG, uma paciente que já havia perdido sete bebês em virtude de incompatibilidade uterina que lhe impedia a manutenção da gravidez até o fim, hoje tem uma filha, nascida em 
2003, fruto de material genético seu e de seu marido, cuja gestação se deu no útero de uma amiga do casal (SÁ; TEIXEIRA, 2005, p. 44).

Todavia, existem questões imbricadas com relação ao momento posterior ao nascimento da criança. O estabelecimento da filiação do nascido fruto de gestação de substituição desafia institutos estabelecidos no direito brasileiro, por exemplo, a presunção de maternidade pelo parto. Conquanto o ordenamento brasileiro não discipline que a parturiente é a mãe (TEIXEIRA, 2004, p. 317), o brocardo romano mater semper certa est faz parte da tradição jurídica brasileira, gerando a presunção de que aquela que dá à luz a criança é sua genitora. Por tal razão, o Estatuto da Criança e do Adolescente determina em seu art. 10, II que hospitais e demais estabelecimentos de atenção à saúde de gestantes, públicos e particulares, são obrigados a identificar o recém-nascido com a sua impressão digital e a da mãe (no caso, a parturiente).

Tendo em vista a inscrição do nome da parturiente na declaração de nascido vivo da criança, para um posterior registro civil que a exclua de seu vínculo de filiação poderia haver dificuldades, como a do caso goiano divulgado pela mídia, no qual os pais não haviam logrado registrar o nascimento da filha quando ela já contava com um ano e seis meses de vida, em virtude de entraves judiciários (ZAGO; CARVALHO, 2012).

De outro lado, existe também a possibilidade de um conflito positivo de maternidade entre a parturiente e aquela que, a princípio, teve a intenção de ser mãe e buscou a realização da técnica (TEIXEIRA, 2004, p. 316-321). Convém relembrar que não necessariamente há vínculo genético de nenhum dos pais intencionais com a criança - vez que é possível o uso de gameta tanto da própria gestante, quanto de quem busca a técnica ou, ainda, de doadores anônimos - de modo que nenhuma das questões poderia ser necessariamente resolvida com base no liame genético entre os envolvidos.

Exatamente por essa razão, o Conselho Nacional de Justiça publicou o Provimento n. ${ }^{\circ}$ 52, em 14 de março de 2016, com o intuito de uniformizar os procedimentos para o registro civil de crianças oriundas de técnicas de reprodução assistida, em todo o território nacional. Referido Provimento, dentre outras determinações, dispensa autorização judicial para inscrição no registro; dita expressamente que o nome da parturiente, constante da declaração de nascido vivo, não deverá constar desse registro; e veda aos oficiais registradores a recusa do registro e de emissão de certidão. Além disso, estabelece que os documentos indispensáveis no caso da gestação de substituição são apenas os seguintes: 
Art. $2^{\circ}$. (...) I - declaração de nascido vivo - DNV;

II - declaração, com firma reconhecida, do diretor técnico da clínica (...) indicando a técnica adotada, o nome do doador ou da doadora, com registro de seus dados clínicos de caráter geral e características fenotípicas, assim como o nome dos beneficiários; ${ }^{3}$

(...) $\S 1^{\circ}$ Nas hipóteses de (...) gestação de substituição, deverão ser também apresentados:

I - termo de consentimento prévio, por instrumento público, do doador ou doadora, autorizando, expressamente, que o registro de nascimento da criança a ser concebida se dê em nome de outrem;

II - termo de aprovação prévia, por instrumento público, do cônjuge ou de quem convive em união estável com o doador ou doadora, autorizando, expressamente, a realização do procedimento de reprodução assistida;

III - termo de consentimento, por instrumento público, do cônjuge ou do companheiro da beneficiária ou receptora da reprodução assistida, autorizando expressamente a realização do procedimento (CONSELHO NACIONAL DE JUSTIÇA, 2016).

Em suma, a norma promove grande facilitação para aqueles que buscam as técnicas de reprodução humana assistida, ao suprir lacuna normativa que gerava situações de absoluta insegurança jurídica, referente ao registro civil no país, momento posterior ao nascimento da criança. ${ }^{4}$ Contudo, cabível perquirir se a aplicação dessa norma poderá se dar de maneira irrestrita, inclusive nos casos em que se realize a prática sem atender aos requisitos da norma administrativa atualmente vigente no Brasil.

\subsection{Quando a gestação de substituição ocorre em desconformidade às exigências da Resolução n. ${ }^{\circ}$ 2.121/2015 do Conselho Federal de Medicina}

Como visto, no Brasil não há legislação federal expressa acerca da prática de gestação de substituição, mas está em vigor norma deontológica do CFM que estabelece uma série de requisitos para sua realização, como a existência de parentesco consanguíneo entre a gestante e quem busca o procedimento, a autorização prévia do Conselho nos demais casos, e a ausência de caráter lucrativo ou comercial.

\footnotetext{
${ }^{3}$ Há também a exigência do inciso III do art. $2^{\circ}$, de comprovação do casamento ou união estável do casal, que se aplica apenas aos casos que i) não digam respeito a famílias monoparentais ou em que ii) apenas um dos cônjuges/companheiros comparecerá ao local do registro.

4 O registro da criança pode se dar de três formas: i) registro no Brasil, nos termos do mencionado Provimento n. ${ }^{\circ} 52$ do CNJ; ii) pelo traslado de assento estrangeiro de nascimento de brasileiro, lavrado por autoridade consular brasileira, tratado pelo art. $8^{\circ}$ da Resolução $\mathrm{n}$. 155/2012 do CNJ; ou iii) pela homologação de sentença estrangeira que estabeleça um vínculo de filiação fruto de gestação de substituição, perante o Superior Tribunal de Justiça. O primeiro tipo é o enfoque deste trabalho, contudo, menciona-se que para realização do segundo tipo o controle de legalidade realizado pelo oficial registrador e pela autoridade consular deverá ser o mesmo que no primeiro. Já o terceiro, homologação de sentença estrangeira, foi analisado por Cláudia Maria Resende Neves Guimarães, cuja leitura se recomenda - sendo de relevo destacar que no julgamento do caso "SENTENÇA ESTRANGEIRA 4.525 - US (2009/0077159-0)" o STJ tangenciou o tema da gestação de substituição, autorizando a homologação de sentença estrangeira de adoção de criança fruto de gestação de substituição onerosa, realizada no Estado de Illinois - EUA (GUIMARÃES, 2014).
} 
É claro o objetivo da Resolução do CFM: pressupõe-se que a consanguinidade, a relação de parentesco entre a gestante substituta e quem busca a técnica, é garantia de que a prática se dará de maneira exclusivamente altruísta; nos demais casos, o órgão médico averiguará se a relação entre os envolvidos permite excluir a possibilidade de qualquer avença comercial entre eles. No Parecer-Consulta n. ${ }^{\circ}$ 5505/2015 do Conselho Regional de Minas Gerais, e no Parecer Consulta n. ${ }^{\circ}$ 13/2014 do Conselho de Goiás, respectivamente, foram autorizados procedimentos em que uma amiga gestaria por outra: ${ }^{5}$

\begin{abstract}
A paciente nem seu parceiro nao tem parentes consanguíneos disponíveis para realização da técnica de útero de substituição, sendo assim, sua amiga L.A.L., divorciada, se propôs submeter-se ao tratamento de útero de substituição, de maneira altruísta (CONSELHO REGIONAL DE MEDICINA DE MINAS GERAIS, 2015).

No caso em tela, o casal solicitante apresenta pessoa amiga que se dispõe ceder temporariamente o útero para que seja realizada fertilização assistida com óvulos e embriões que foram congelados em tentativas anteriores pela solicitante, onde não se obteve sucesso. A doadora foi avaliada pelo médico que irá fazer o procedimento, Dr. W. N. A., o qual informa estar ela em condições clínicas favoráveis, assim como não foi identificada qualquer vantagem dela em relação ao casal solicitante (CONSELHO REGIONAL DE MEDICINA DE GOIÁS, 2014).
\end{abstract}

Assim, não obstante inexista no país expressa proibição ao caráter comercial da técnica de gestação de substituição, é possível identificar-se uma tradição que, em geral, ${ }^{6}$ obsta a valoração financeira de partes do corpo, como ocorre no caso do art. 15 da Lei n. ${ }^{\circ}$ 9434/1997 - sobre a doação ou remoção de órgãos, tecidos e partes do corpo humano para fins de transplante e tratamento -, o qual estabelece pena de reclusão de três a oito anos para aquele que compra ou vende "partes humanas".

A Resolução n. ${ }^{\circ}$ 2.121/2015 do CFM, portanto, impõe às pessoas que necessitam do uso da técnica a difícil missão de encontrarem mulher que se disponha a enfrentar todas as vicissitudes de uma gravidez - enjoos, dores, atendimento às exigências do pré-natal, repouso que pode implicar o afastamento temporário do emprego, riscos inerentes à saúde da gestante no parto, etc. - e, ao final, entregar a criança aos pais intencionais, sem que possa receber absolutamente nada como contraprestação. Dessa forma, mesmo aqueles que têm parentes consanguíneas aptas para a gestação, o que certamente representa uma minoria, não têm garantia de que estarão dispostas a tanto.

\footnotetext{
5 Já se autorizou, inclusive, que uma funcionária gestasse pela empregadora, no Parecer n. ${ }^{\circ}$ 5501/2015 do CRMMG, considerando-se suficiente um termo de próprio punho dos envolvidos reconhecendo o caráter altruísta da prática para que fosse deferida pelo Conselho: "A paciente A.R.M. teve diagnóstico aos 15 anos de agenesia uterina, não podendo assim gestar, tendo indicação de fertilização in vitro com útero de substituição. (...) Este casal ainda apresenta 2 embriões criopreservados e deseja agora nova gestação. Entretanto, devido a razões médicas, A. não poderá tentar nova gestação. Não havendo mais parentes do casal com possibilidades de gestar, o casal trouxe uma funcionária de A.R.M. como candidata a útero de substituição" (CONSELHO REGIONAL DE MEDICINA DE MINAS GERAIS, 2015).

6 Diz-se "em geral" porque há transações com "partes do corpo humano" permitidas e usualmente praticadas no país, como é o caso da compra e venda de cabelo e de diversos hormônios humanos (STANCIOLI, 2013).
} 
A exigência de que inexista caráter comercial, quando a gravidez de substituição trará para a gestante riscos que em muito ultrapassam o simples desconforto, por vezes torna impossível a prática, tendo em vista a dificuldade para encontrar quem se disponha a fazê-lo nesses moldes. Em tais casos, duas alternativas se apresentam: a realização da prática no próprio país, mas em desrespeito às exigências do CFM; ou a sua realização fora do Brasil, em algum outro país que permita o pagamento de contraprestação à gestante, como fez a atriz brasileira Adriana Garambone, que após dois abortos naturais procurou uma agência de Israel para ter um filho nascido no Nepal (GUIDORIZZI, 2015), onde a onerosidade de um contrato de gestação de substituição é permitida - e a gestante pode receber até nove mil dólares (KLINKE, 2015).

É certo que a existência de legislações díspares em um mundo globalizado tem gerado o chamado forum shopping, um "mercado de direitos" (RODOTÀ, 2010, p. 74) ou, no que tange especificamente às técnicas de reprodução assistida, um "turismo reprodutivo" (GUIMARÃES, 2014). Por essa razão, Rodotà critica uma "cidadania nacional”, que ao unir os nacionais de um país, termina por excluir aqueles de fora (2010, p. 73-74). Assim, a busca por legislações mais permissivas - possível, porque há livre trânsito de pessoas em nosso mundo globalizado - tem sido o principal motivo que leva muitos a se dirigir a outros países para acesso às técnicas de reprodução, embora também figurem como motivações, em menor medida, a pouca disponibilidade de doadores e centros de reprodução no próprio país, ou ainda a busca por maior qualidade/menor preço (GOMEZ; ROCHEBROCHARD, 2014, p. 3104).

Veja-se que em São Paulo já existem agências como a "Tammuz", do israelense Roy Rosenblatt-Nir, especializadas em viabilizar a realização onerosa do procedimento em outros países. Em julho de 2015 tal agência já possuía "25 processos de brasileiros em andamento, sendo 14 de casais gays, sete de casais heterossexuais e sete de solteiros" (KLINKE, 2015). É também curioso notar que o website "www.surrogatefinder.com" possui inscrição de um sem número de brasileiras que especificam em suas descrições que buscam atuar como gestantes de substituição especialmente pela remuneração financeira. ${ }^{7}$ No Brasil, portanto, há muitas pessoas dispostas a pagar, e tantas outras dispostas a receber pelo procedimento.

\footnotetext{
7 Em pesquisa realizada em 27 de março de 2016, restringindo-se o campo de pesquisa para Belo Horizonte/MG, havia 40 mulheres inscritas no website disponibilizando-se para atuação como gestantes de substituição; $45 \%$ delas com expresso objetivo de receber remuneração financeira, mormente para "comprar uma casa", "financiar estudos" ou por "estar desempregada". Por exemplo, do perfil de uma candidata consta: "Meu nome é Denise, tenho 36 anos. Sou casada e mãe de um menino lindo e saudável de 07 anos. Eu realmente gostaria muito de ajudar outros casais a realizar o sonho de ter um bebé. Isso me deixaria muito feliz também pois eu ajudo o casal e eles também me ajudam com a parte financeira pois no momento preciso muito do dinheiro também” (sic).
} 
Isso exposto, pergunta-se: no caso de criança nascida em desconformidade à vigente norma do CFM - por exemplo, sem o exigido caráter altruísta - o registro poderá ser feito nos facilitados termos do Provimento n. 52 do CNJ? Para buscar responder tal questão, é relevante o estudo de recentes decisões do Tribunal Supremo da Espanha, tratadas detalhadamente no próximo item.

\section{REGISTRO DO NASCIDO A PARTIR DE GESTAÇÃO DE SUBSTITUIÇÃO: PANORAMA ESPANHOL}

A Espanha está entre os países europeus que não autorizam, sob qualquer hipótese, a gestação de substituição. O art. 10 da Lei n. ${ }^{\circ}$ 14/2006 (lei sobre técnicas de reprodução humana assistida) é expresso no sentido de que o "contrato" pelo qual se convenciona a gestação de substituição, com ou sem preço, é nulo de pleno direito, bem como determina a aplicação de presunção absoluta de maternidade pelo parto (ESPANHA, 2006).

Por essa razão, espanhóis que desejam recorrer à técnica dirigem-se a outros países onde ela é permitida, a fim de praticá-la, em exercício de seu direito ao livre planejamento familiar. No entanto, encontram entraves ao buscar o registro espanhol do filho fruto da gestação de substituição, ${ }^{8}$ seja no Consulado Espanhol no país de nascimento, seja em Cartórios de Registro Civil na Espanha.

A argumentação das autoridades para o impedimento do registro espanhol da criança foi explicitada no julgamento de um recurso de cassação pelo Tribunal Supremo do país, em 06 de fevereiro de 2014, referente à situação de um casal homoafetivo que recorreu à gestação de substituição na Califórnia, Estados Unidos (ESPANHA, 2014).

Inicialmente, os Srs. Estanislao e Gines dirigiram-se à cidade de Los Angeles, onde a legislação autoriza a gestação de substituição, inclusive onerosa, e formalizaram contrato referente à prática. Nascendo gêmeos, solicitaram junto ao Consulado Espanhol na cidade, em 7 de novembro de 2008, o registro deles como seus filhos (o que, por conseguinte, torná-los-ia cidadãos espanhóis), apresentando certificação americana de que ambos eram os pais das

\footnotetext{
8 A dificuldade de obtenção do registro espanhol é o efeito de enfoque do presente trabalho, mas não é o único entrave que se apresenta no caso de filhos fruto de gestação de substituição. Nesse sentido, registra-se que há também embates judiciais acerca da "prestación por maternidad" - benefício financeiro concedido pelo governo espanhol à pessoa que tenha dado à luz, adotado ou acolhido um infante -, que tem sido concedida em casos de gestação de substituição apenas em alguns casos (NAVARRO, 2015, p. 39), com oscilação da jurisprudência.
} 
crianças. A requisição foi negada pela autoridade local, ao argumento de que, por aplicação da legislação espanhola, a parturiente deveria ser considerada mãe biológica dos meninos e o contrato de gestação de substituição por eles celebrado seria nulo de pleno direito.

Tendo recorrido administrativamente junto à Direção Geral de Registros e Notariado da Espanha, em 2009 foi ordenado o registro dos gêmeos como filhos do casal. Contudo, o Ministério Fiscal espanhol, no exercício de controle de legalidade, impugnou referida determinação perante o Judiciário, logrando tornar sem efeito o registro que houvera sido feito.

O casal interpôs recurso de apelação, o qual foi julgado em 23 de novembro de 2011 ratificando a decisão da instância primeva, isto é, mantendo sem efeito o registro das crianças como filhos do casal. Assim, interpuseram Recurso de Cassação perante o Tribunal Supremo, contra a sentença confirmada em apelação, aduzindo violação ao princípio da igualdade, diretamente ligado ao direito das duas crianças à identidade e à busca por seu melhor interesse, bem como que, conquanto na Espanha seja nulo o contrato de gestação de substituição, não esperavam o reconhecimento dele, mas sim de um "efeito periférico", o registro.

Em 06 de fevereiro de 2014, o Tribunal analisou a questão posta a partir da análise sobre se acatar o registro, na Espanha, de crianças fruto de gestação de substituição, respeitaria a ordem pública internacional espanhola, "entendida basicamente como o sistema de direitos e liberdades individuais garantidos pela Constituição e pelos convênios internacionais de direitos humanos ratificados pelo país" (ESPANHA, 2014). Ao final, consideraram por maioria que a ordem pública restaria, sim, violada, tendo em vista que a lei que expressamente proibiu a gestação de substituição seria "recente" (de 2006) e elaborada a partir de intenso debate social, bem como porque:

(...) os avanços das técnicas de reprodução humana assistida vulneram a dignidade da mulher gestante e da criança, mercantilizando a gestação e a filiação, "coisificando" a mulher gestação e a criança, permitindo a determinados intermediários realizar negócio com eles, possibilitando a exploração do estado de necessidade em que se encontram mulheres jovens em situação de pobreza e criando uma espécie de "cidadania censitária" na qual somente aqueles que dispõem de elevados recursos econômicos podem estabelecer relações paterno-filiais vedadas à maioria da população (ESPANHA, 2014, tradução nossa). ${ }^{9}$

\footnotetext{
9 Texto original: “(...) los avances en las técnicas de reproducción humana asistida vulneren la dignidad de la mujer gestante y del niño, mercantilizando la gestación y la filiación, "cosificando" a la mujer gestante y al niño, permitiendo a determinados intermediarios realizar negocio con ellos, posibilitando la explotación del estado de necesidad en que se encuentran mujeres jóvenes en situación de pobreza y creando una especie de "ciudadanía censitaria" en la que solo quienes disponen de elevados recursos económicos pueden establecer relaciones paterno-filiales vedadas a la mayoría de la población”.
} 
Além disso, o Tribunal concluiu que o registro da filiação não corresponderia apenas a um "efeito periférico" do contrato, porque violaria frontalmente outra disposição expressa do art. 10 da Lei n. ${ }^{\circ}$ 14/2006, relativo à determinação de maternidade pelo parto. Quanto à desigualdade oriunda da permissão de registro caso se tratasse de casal homoafetivo feminino (já que, diferentemente de um casal masculino, uma delas pode se utilizar de seu próprio útero para gestar o bebê), expôs apenas que a desigualdade substancial que, nesse caso, existe entre homens e mulheres, autorizaria o tratamento também desigual.

Enfrentou-se ainda o importante argumento referente à alegada violação ao superior interesse das crianças. Os recorrentes aduziram que a ausência de registro deixaria os menores desprotegidos e representaria afronta à sua identidade, bem como que ambos, por serem os pais intencionais, seriam melhores que a mulher que os gestou exclusivamente em virtude de uma relação contratual. O Tribunal, por sua vez, não acatou o argumento por entender que esse "superior interesse" é cláusula aberta que admite interpretações distintas que, a uma, devem ter em conta outros bens jurídicos (como a proibição da mercantilização da gestação) e, a duas, em hipótese alguma afrontar expressa disposição de lei.

Por isso, o Tribunal aduziu que a proteção jurídica dos gêmeos poderia se dar de maneira legalmente reconhecida na Espanha, qual seja, a partir do reconhecimento da situação "de fato" daquela família (adoção ou acolhimento); ou ainda, no caso de algum dos recorrentes ter cedido seu material biológico para a fecundação, reclamar a paternidade biológica, com posterior pedido de adoção pelo cônjuge - ressaltando o Tribunal que até que uma dessas medidas judiciais se efetivasse, os menores não estariam privados de nome ou nacionalidade, mas apenas da filiação almejada pelos recorrentes.

Face à referida decisão o casal promoveu novo recurso - a fim de ensejar a nulidade do acórdão do Tribunal Supremo, por violação de direitos fundamentais dos recorrentes - o qual fora julgado em 02 de fevereiro de 2015, levando em conta dois casos semelhantes (Mennesson vs. França e Labasseé vs. França), julgados pelo Tribunal Europeu de Direitos Humanos - TEDH ou Tribunal de Estrasburgo, em julho de 2014, pelos quais o TEDH determinou que a França, não obstante também considerasse nulos os contratos de gestação de substituição, empreendesse o registro de crianças com pais intencionais franceses, nascidas a partir dessa técnica.

Por essa razão, o Tribunal Supremo da Espanha analisou as semelhanças e diferenças existentes entre o caso espanhol e os dois casos franceses julgados pelo TEDH, concluindo 
pela inexistência de similitude e, por conseguinte, pela inocorrência de afronta a direitos fundamentais e nulidade no julgamento.

Nesse sentido, considerou que o ordenamento espanhol protegia melhor o interesse das crianças que o ordenamento francês (AYAGO, 2015, p. 56), uma vez que, nos julgados franceses, o Tribunal daquele país havia considerado que do uso da técnica da gestação de substituição decorreria um vício de origem que impediria qualquer formação de vínculo entre os pais intencionais e os filhos, de modo que nem mesmo pelas demais vias - de reconhecimento de paternidade biológica de um deles com posterior adoção pelo outro cônjuge, ou ainda, adoção ou acolhimento por ambos - seria possível o reconhecimento do vínculo de filiação.

Para o Tribunal, o mesmo não teria ocorrido no julgamento espanhol, que destacou a possibilidade de reconhecimento com fulcro em outros tipos de vínculo de filiação, de modo que, no seu entender, não haveria prejuízos ao interesse dos infantes:

O acórdão desta Sala não anula a inscrição da filiação de crianças nascidas de uma gestação por substituição referente aos comitentes para lhes obrigar a dar uma volta, "cumprir algumas formalidades" e chegar ao mesmo ligar. A questão decisiva é que o que determina a relação de filiação, essencial para estabelecer a identidade do menor, segundo as normas de ordem pública do ordenamento espanhol atualmente vigentes porque o legislador entendeu ser o mais adequado para proteger o interesse do menor, é a filiação biológica (...), e o estabelecimento de laços filiais como consequência da existência de um núcleo familiar de fato em que estejam integrados os menores, o genitor biológico e seu cônjuge, como por exemplo os derivados da adoção, na qual o interesse do menor é controlado e protegido pelo juiz que a determina (art. 176 do Código Civil). (...) Os desconfortos e inconvenientes causados aos recorrentes (e em menor medida para as crianças, que por sua pouca idade não terão sequer consciência da situação) podem envolver a situação provisória produzida pela substituição da filiação resultante do transcrição das atas de nascimento na Califórnia pela filiação oriunda da aplicação das normas do ordenamento jurídico espanhol, não alcançam importância suficiente para se considerar a existência de desequilíbrio violado do direito à vida privada dos infantes, em seu aspecto de fixação de uma identidade determinada. Trata-se de uma situação provisória que pode ter duração razoavelmente breve (...) (ESPANHA, 2014, tradução nossa). ${ }^{10}$

\footnotetext{
10 Texto original: "La sentencia de esta Sala no anula la inscripción de la filiación de los niños nacidos de una gestación por sustitución respecto de los comitentes para obligarles a dar un rodeo, "cumplir unas formalidades" y llegar al mismo sitio. La cuestión decisiva es que lo que determina la relación de filiación, esencial para establecer la identidad del menor, según las normas de orden público del ordenamiento español actualmente vigentes porque el legislador ha entendido que es lo más adecuado para proteger el interés del menor, es la filiación biológica (...), y el establecimiento de lazos filiales como consecuencia de la existencia de un núcleo familiar de facto en el que estén integrados los menores, el progenitor biológico y su cónyuge, como por ejemplo los derivados de la adopción, en la que el interés del menor se controla y protege por el juez que la constituye (art. 176 del Código Civil). (...) Las molestias e inconvenientes que para los recurrentes (y en menor medida para los niños, que por su corta edad no serán conscientes siquiera de la situación) puede suponer la situación provisional que se produzca por la sustitución de la filiación resultante de la transcripción de las actas de nacimiento de California por la filiación que resulte de la aplicación de las normas del ordenamiento jurídico español, no alcanzan una entidad suficiente como para considerar que se produce el desequilibrio vulnerador del derecho a la vida privada de los niños, en su aspecto de fijación de una identidad determinada. Se trata de una situación temporal que puede tener una duración razonablemente breve (...)".
} 
No interregno entre a condenação da França pelo TEDH, em julho de 2014, e a decisão do Tribunal Supremo da Espanha no mencionado incidente de nulidade, o Senado espanhol engendrou esforços no sentido de promover alteração na legislação registral do país, a fim de permitir o registro civil de crianças fruto da técnica de gestação de substituição realizada em outros países. Contudo, com a decisão do Supremo espanhol em 2015, a alteração legal não mais ocorrerá (AYAGO, 2015, p. 61).

Os catedráticos espanhóis Alfonso-Luis Calvo Caravaca e Javier Carrascosa González apresentaram ferrenhas críticas às decisões espanholas em sede de recurso de cassação e incidente de nulidade. Destacaram que as soluções apresentadas pelo Tribunal Supremo como "alternativas" para o registro das crianças seriam, na verdade, falsas soluções, uma vez que necessariamente acarretariam prejuízos aos nascidos:

a) à sua vida privada e identidade, vez que teriam nomes e pais distintos nos Estados Unidos (onde figurariam os pais intencionais) e na Espanha (onde estaria a parturiente e talvez um dos pais, caso tenha havido doação de material genético por um deles), inclusive "perdendo" um pai (ou dois) para se sobrepor uma mãe que já havia expressamente renunciado à autoridade parental (2015, p. 88-89);

b) à sua nacionalidade espanhola, vez que seu reconhecimento depende do vínculo de filiação com cidadão espanhol (2015, p. 89), o que ficaria pendente até que outro vínculo, dentre os sugeridos pelo próprio Tribunal, fosse estabelecido;

c) a seus direitos sucessórios, vez que não estarão na condição de filhos dos pais intencionais, de modo que apenas herdarão se postos como seus legatários $(2015$, p. 90);

d) acima dos demais, há graves prejuízos à proteção dos infantes e de seu superior interesse, uma vez que, ainda que seja o Ministério Fiscal espanhol o responsável por mover a ação, ninguém pode ser obrigado a adotar uma criança, como deveria ocorrer com um dos pais intencionais caso o outro fosse o genitor biológico, ou com ambos, caso não houvesse vínculo biológico com nenhum deles. Sendo assim, se um dos pais, ou ambos, "mudarem de ideia" - como, infelizmente, é plausível acontecer no caso de o menor gestado nascer com alguma espécie de deficiência -, eles não poderão ser compelidos a fazê-lo, dificultando sobremaneira a proteção do infante (2015, p. 93). Por outro lado, no caso de o registro espanhol automaticamente assumir o que consta do registro no país onde nasceu, a criança estará legalmente protegida desde o nascimento.

Além disso, os autores asseveram que a posição do Tribunal Espanhol espelhou, na verdade, um "inferior interesse do menor", tendo em vista que no momento da identificação hierárquica do princípio de seu superior interesse em face de outros comandos da ordem pública 
internacional espanhola, não se levou em conta a supremacia da qual ele é digno, dando preferência à letra da lei e deixando de considerar os efetivos prejuízos causados:

\begin{abstract}
O princípio do "interesse superior do menor" está presente em textos legais internacionais como a Convenção sobre os direitos da criança de 20 de novembro de 1989. Esse princípio se reflete, portanto, em textos legais que dispõem de uma claríssima preferência de aplicação, se comparado a uma lei espanhola como é a Lei 14/2006. Dito princípio deve ser aplicado na solução de casos litigiosos com preferência ao disposto na mencionada Lei por razões de hierarquia normativa e de hierarquia valorativa. Esse princípio não constitui uma pauta extralegal que destrói ou pode destruir o que estabelece a lei positivada espanhola. Pelo contrário: este princípio está presente em normas jurídicas claríssimas do Direito espanhol, normas que devem ser aplicadas preferentemente ao que indicam as leis espanholas. Portanto, as leis espanholas são as que devem se ajustar, em sua formulação escrita e na sua aplicação prática, a esse princípio, nos casos concretos (CARAVACA; GONZÁLEZ, 2015, p. 81, tradução nossa). ${ }^{11}$
\end{abstract}

Como se observou, o acórdão de cassação não teve votação unânime. O voto minoritário, que ao todo foi esposado por quatro magistrados, fez ressaltar que o princípio do superior interesse do menor é também conteúdo da ordem pública internacional espanhola, identificando que naquele caso a decisão majoritária violava tal interesse ao "colocar-lhes em um limbo incerto quanto à solução do conflito, enquanto crescem e criam laços afetivos e familiares irreversíveis" (ESPANHA, 2014). Mais além, asseverou-se quanto ao princípio da igualdade que "o caráter ilegal de uma filiação não justifica nenhum trato diferenciado por parte de autoridades públicas ou instituições privadas”.

Tal qual na Espanha, o Poder Judiciário de outros países europeus que proíbem a gestação de substituição em qualquer hipótese (como a França e a Alemanha) - assim como o Tribunal Europeu de Direitos Humanos, já mencionado - também têm sido instados a se manifestar sobre a questão do registro nos casos em que a prática é realizada por seus cidadãos fora de sua jurisdição. Tendo em vista a incipiência da discussão no âmbito brasileiro, a compreensão da resposta dada por esses países - e de suas fragilidades - serve de amparo àquela que se entende deva ser dada por nosso ordenamento, como se busca demonstrar a seguir.

\footnotetext{
11 Texto original: "El principio del "interés superior del menor" está contenido en textos legales internacionales como la Convención sobre los derechos del niño de 20 noviembre 1989. Este principio se recoge, por tanto, en textos legales que disponen de una claríssima preferencia aplicativa sobre una Ley española como es la Ley 14/2006. Dicho principio debe aplicarse en la solución de los casos litigiosos con preferencia a lo dispuesto en dicha Ley por razones de jerarquia normativa y de jerarquía valorativa. Este principio no constituye una pauta extra-legal que destruye o puede destruir lo que establece la Ley positiva española. Todo lo contrario: este principio está contenido en normas jurídicas clarísimas del Derecho español, normas que deben aplicarse con preferencia a lo que indican las leyes españolas. Por ello, las leyes españolas son las que deben ajustarse, en su formulación escrita y en su aplicación práctica, a dicho principio, todo ello en el caso concreto".
} 


\section{CONCLUSÃO: A NORMATIVA FACILITADA DO PROVIMENTO n. ${ }^{\circ} 2$ DO CNJ DEVE SER APLICÁVEL AOS CASOS EM QUE A GESTAÇÃO DE SUBSTITUIÇÃO OCORRE EM DESCONFORMIDADE ÀS EXIGÊNCIAS DA RESOLUÇÃO n. ${ }^{\circ}$ 2.121/2015 DO CFM?}

Brasil e Espanha diferenciam-se em um ponto crucial quanto à prática da gestação de substituição: enquanto naquele país há proibição expressa, por lei, da prática em qualquer hipótese, aqui não há legislação federal que expressamente a proíba, tanto assim que, no momento, vige Resolução administrativa que permite a médicos praticarem-na, sob determinadas condições, dentre elas a da ausência de caráter lucrativo ou comercial na relação entre a gestante e os chamados pais intencionais (bem como a existência de relação de parentesco que, como se viu, tem também o propósito de buscar garantir o altruísmo da prática).

Todavia, como se expôs, a proibição do caráter comercial por referida Resolução condiz com uma tradição jurídica brasileira no sentido de obstar valorações financeiras de partes do corpo humano, a exemplo da lei sobre a doação ou remoção de órgãos, tecidos e partes do corpo humano para fins de transplante e tratamento, que tipifica como crime a compra ou venda de "partes humanas".

Não é proposta deste trabalho a análise da validade ou invalidade ético-jurídica da proibição de um tal comércio, mas sim a de identificar se - considerando-se que a atual normatividade brasileira, depreendida de uma análise sistemática do ordenamento, rejeita que partes do corpo humano sejam alvo de transações financeiras - o registro de uma criança que tenha nascido fruto de gestação de substituição cujo altruísmo não fora necessariamente comprovado poderá, ou não, se dar segundo os facilitados moldes do recém-publicado Provimento n. ${ }^{\circ} 52$ do CNJ.

A resposta é positiva.

Da análise dos argumentos esposados pelo Tribunal Supremo da Espanha, e de suas fragilidades, pôde-se depreender que ainda que a prática da gestação de substituição seja absoluta e expressamente proibida naquele país, proporcionar qualquer espécie de entrave ao registro gera prejuízos inaceitáveis à criança - à personalidade, identidade, vida privada, nacionalidade e direitos sucessórios, além de deixá-las à mercê da vontade dos pais intencionais de posteriormente adotá-las, o que gera enorme insegurança jurídica -, quando seu superior interesse deve ser colocado como objetivo primordial, na linha do que fora esposado pelo 
Tribunal Europeu de Direitos Humanos ao decidir sobre os mencionados casos franceses Mennesson e Labasseé.

Por sua vez, no Brasil, tem-se que a realização de uma prática, no país ou fora dele, em desconformidade com os requisitos postos pelo Conselho Federal de Medicina nem mesmo é efetivamente proibida. Contudo, à luz do estudado, ainda que viesse a sê-lo, não se poderia admitir qualquer entrave ao registro.

A uma, porque o livre trânsito dos cidadãos brasileiros pelo mundo, autorizado pelo Estado brasileiro (e pelo espanhol), viabiliza a realização do procedimento em qualquer outro país e, portanto, o uso e gozo de um "mercado de direitos" (RODOTÀ, 2010, p. 74) - situação que se tornou típica em nosso mundo globalizado, e que cada vez mais está a enfraquecer as fronteiras dos modernamente chamados Estado-Nação. Não obstante, ainda que houvesse alguma ilicitude na prática dos pais intencionais, a sanção correspondente não poderia atingir a esfera jurídica de proteção da criança, o que apenas reforça que o registro de seu nascimento deve ser o mais facilitado possível. A duas, por ser impossível admitir dificuldades registrais causadoras de graves prejuízos ao melhor interesse das crianças: como se depreendeu das críticas aos acórdãos espanhóis, uma vez que o registro significa proteção jurídica imediata de pessoas para as quais os ordenamentos brasileiro, espanhol e internacional voltam proteção singular, uma tal proteção não pode deixar de ser incessantemente promovida.

\section{REFERÊNCIAS BIBLIOGRÁFICAS}

ALMEIDA, Renata Barbosa de. Direito ao planejamento familiar e o choque de consentimentos sobre o uso dos embriões: o caso Evans versus Reino Unido sob a égide do direito brasileiro. Lex medicinae. Coimbra Editora, Ano 6, n. 12, jul-dez. 2009. p. 91-107.

AYAGO, Antonia Durán. Una encrucijada judicial y una reforma legal por hacer: problemas jurídicos de la gestación por sustitución en España. A propósito del auto del Tribunal Supremo de 2 de febrero de 2015. Bitácora Millenium DIPr, n. 2, p. 50-63, set. 2015. Disponível em: <http://www.millenniumdipr.com/archivos/1441706352.pdf>. Acesso em: 29 mar. 2016.

CARAVACA, Alfonso-Luis Calvo; GONZÁLES, Javier Carrascosa. Gestación por sustitución y derecho internacional privado: más allá del Tribunal Supremo y del Tribunal Europeo de Derechos Humanos. Cuadernos de Derecho Transnacional, v. 7, n. 2, p. 45-113, out. 2015. Disponível em: <http://e-revistas.uc3m.es/index.php/CDT/article/viewFile/2780/1558>. Acesso em: 29 mar. 2016. 
CONSELHO FEDERAL DE MEDICINA. Resolução CFM n..$^{\mathbf{2 1 2 1}}$ 2015, que adota as normas éticas para a utilização das técnicas de reprodução assistida. Disponível em: <http://www.portalmedico.org.br/resolucoes/CFM/2015/2121_2015.pdf >. Acesso em: 30 mar. 2016.

CONSElHO NACIONAL DE JUSTIÇA. Provimento n. ${ }^{\circ}$ 52, de 14 de março de 2016, que dispõe sobre o registro de nascimento e emissão da respectiva certidão dos filhos havidos por reprodução assistida. Disponível em:

<http://www.cnj.jus.br/files/conteudo/arquivo/2016/03/6bd953c10912313a24633f1a1e6535e1

.pdf>. Acesso em: 29 mar. 2016.

CONSELHO REGIONAL DE MEDICINA DE GOIÁS. Parecer-consulta n. ${ }^{\circ}$ 13/2014: Processo Consulta n. ${ }^{\circ}$ 06/2014. Rel. Aldair Novato Silva. 28. jul. 2014. Disponível em: $<$ http://www.cremego.cfm.org.br/index.php?option=com_content \&view=article\&id $=27023 \%$ 3Aparecer-autoriza-uso-de-utero-de-substituicao-com-doadora-sem-parentesco-com-ocasal\&catid=3\&Itemid=491>. Acesso em: 29 mar. 2016.

CONSELHO REGIONAL DE MEDICINA DE MINAS GERAIS. Parecer-consulta n. ${ }^{\circ}$ 5501/2015. Rel. Cláudia Navarro Carvalho Duarte Lemos. 09. mar. 2015. Disponível em: <http://www.portalmedico.org.br/pareceres/crmmg/pareceres/2015/5501_2015.pdf>. Acesso em: 29 mar. 2016.

Parecer-consulta n. ${ }^{\circ}$ 5505/2015. Rel. Giovana Ferreira Zanin Gonçalves. 30 abr.

2015. Disponível em:

<http://www.portalmedico.org.br/pareceres/CRMMG/pareceres/2015/5505_2015.pdf>.

Acesso em: 29 mar. 2016.

ESPANHA. Ley 14/2006, de 26 de mayo, sobre técnicas de reproducción humana asistida. Boletín Oficial del Estado n. 126. Disponível em:

<http://www.boe.es/boe/dias/2006/05/27/pdfs/A19947-19956.pdf>. Acesso em: 28 mar. 2016.

. Tribunal Supremo. Sentencia de casación n. 835-2013, da Sala de lo Civil Pleno, 6 fev. 2014. Disponível em:

<http://www.poderjudicial.es/stfls/PODERJUDICIAL/JURISPRUDENCIA/FICHERO/20140

206\%20TS\%20Civil\%20REC\%20245.2012.pdf>. Acesso em: 25 mar. 2016.

FARIAS, Cristiano Chaves. A família parental. PEREIRA, Rodrigo da Cunha (org.). Tratado de Direito das Famílias. Belo Horizonte: IBDFAM, 2015. p. 247-276.

FIUZA, Cesar; MARQUES, Emanuel Adilson. Hermenêutica civil-constitucional do direito das obrigações. In: FIUZA, Cesar. Elementos de teoria geral das obrigações e dos contratos: por uma abordagem civil-constitucional. Curitiba: CRV, 2012. p. 203-221.

GAMA, Guilherme Calmon Nogueira da. Filiação e reprodução assistida: introdução ao tema sob a perspectiva civil-constitucional. In: TEPEDINO, Gustavo. Problemas de direito civilconstitucional. Rio de Janeiro: Renovar, 2001. p. 515-546.

GÊNESIS. In: Bíblia Sagrada: edição pastoral. São Paulo: Paulus, 1990. 
GOMEZ, Virginie Rozée; LA ROCHEBROCHARD, Elise de. Cross-border reproductive care among French patients: experiences in Greece, Spain and Belgium. Human Reproduction, Bethesda, v. 28, n. 11, p. 3103-3110, ago. 2013. Disponível em:

<http://www.ncbi.nlm.nih.gov/pubmed/23943796>. Acesso em: 25 mar. 2016.

GUIDORIZZI, Guilherme. Atriz da novela 'Os Dez Mandamentos' procurou uma agência de Israel para ter filho nascido no Nepal. Purepeople, 24 dez. 2015. Disponível em: $<$ http://www.purepeople.com.br/noticia/apos-dois-abortos-adriana-garambone-recorreu-abarriga-de-aluguel-para-ser-mae_a92067/1>. Acesso em: 29 mar. 2016.

GUIMARÃES, Cláudia Maria Resende Neves. Homologação de sentença estrangeira: gestação de substituição transnacional, o caso Mennesson e a Ordem Pública no Brasil. Congresso Nacional do XXIII CONPEDI/UFSC, Florianópolis, p. 304-333, 2014. Disponível em: <http://www.publicadireito.com.br/artigos/?cod=6d1be3a2fee80212>. Acesso em: 20 mar. 2016.

GUSTIN, Miracy Barbosa de Sousa; DIAS, Maria Tereza Fonseca. (Re)pensando a pesquisa jurídica. 2. ed. rev., atual. e ampl. Belo Horizonte: Del Rey, 2006.

KLINKE, Angela. Agência de barriga de aluguel abre escritório em São Paulo. Valor Econômico, 29 jul. 2015. Disponível em: <http://www.valor.com.br/cultura/bluechip/4154436/agencia-de-barriga-de-aluguel-abre-escritorio-em-sao-paulo>. Acesso em: 29 mar. 2016.

LAMM, Eleonora. La importancia de la voluntad procreacional en la nueva categoría de filiación derivada de las técnicas de reproducción assistida. Revista de bioética y Derecho, Barcelona, n. 24, p. 76-91, jan. 2012. Disponível em:

<http://www.ub.edu/fildt/revista/RByD24_master.htm>. Acesso em: 29 mar. 2016.

NAVARRO, Sergio Manuel Pérez. Gestación por Sustitución: análisis internacional privatista desde una perspectiva jurisprudencial. 2015. 44f. Trabalho de conclusão de curso (Graduação) - Facultad de Derecho, Universidad Zaragoza, Zaragoza, 2015.

ROBERTO, Giordano Bruno Soares. Introdução à História do Direito Privado e da Codificação: uma análise do novo Código Civil. 2. ed. Belo Horizonte: Del Rey, 2008.

RODOTÀ, Stefano. La vida y las reglas: entre el derecho y el no derecho. Madrid: Trotta, 2010 .

SÁ, Maria de Fátima Freire de; TEIXEIRA, Ana Carolina Brochado. Filiação e biotecnologia. Belo Horizonte: Mandamentos, 2005.

STANCIOLI, Brunello. Lei não prevê crime para venda de óvulos. Consultor Jurídico. 28 abr. 2013. Disponível em: <http://www.conjur.com.br/2013-abr-28/brunello-stancioli-lei-naopreve-crime-venda-ovulos>. Acesso em: 28 mar. 2016. 
TEIXEIRA, Ana Carolina Brochado. Conflito positivo de maternidade e a utilização do útero de substituição. In: CASABONA, Carlos María Romeo; QUEIROZ, Juliane Fernandes (coord.). Biotecnologia e suas implicações ético-jurídicas. Belo Horizonte: Del Rey, 2004. Cap. 13. p. 309-323.

TEPEDINO, Gustavo. A constitucionalização do direito civil: perspectivas interpretativas diante do novo Código. In: NAVES, Bruno Torquato de Oliveira; FIUZA, Cesar; SÁ, Maria de Fátima Freire de (coord.). Direito Civil: atualidades. Belo Horizonte: Del Rey, 2003. p. 115-130.

ZAGO, Adriano; CARVALHO, Humberta. Casal não consegue registrar a filha gerada em barriga de aluguel, em GO. G1 Goiás, 04 set. 2012. Disponível em:

$<$ http://g1.globo.com/goias/noticia/2012/09/casal-nao-consegue-registrar-filha-gerada-embarriga-de-aluguel-em-go.html>. Acesso em: 2 nov. 2015. 